\title{
Desenvolvimento da dimensáo educacional dos Comitês de Ética em Pesquisa (CEPs)
}

Adriana Silva Barbosa ${ }^{1}$, Rita Narriman Silva de Oliveira Boery ${ }^{2}$, Eduardo Nagib Boery ${ }^{3}$, Márcio Roger Ferrari $^{4}$

Resumo: A importância do caráter educativo e consultivo dos Comitês de Ética em Pesquisa (CEPs) torna relevante pesquisas que busquem investigar essas dimensóes dos referidos comitês. Objetivos: analisar como os CEPs têm realizado seu papel educacional e consultivo; averiguar se os pareceristas têm alguma formaçáo sobre ética em pesquisa; identificar se os pesquisadores tiveram orientaçóes sobre ética em pesquisa em sua trajetória acadêmica. Estudo quantitativo e descritivo, aprovado pelo CEP/UESB sob protocolo 134/2009, realizado com 95 informantes e analisado pelo Software Sphinx. De acordo com os dados obtidos, cerca de $71,5 \%$ dos participantes da pesquisa consideram as atividades educativas e consultivas realizadas pelo CEP pouco freqüentes ou inexistentes; $60 \%$ de pareceristas do CEP têm algum tipo de formaçáo ética e $66,7 \%$ dos pesquisadores participantes tiveram alguma abordagem ética na trajetória acadêmica. Estes dados indicam que os CEPs necessitam de maior apoio institucional e investimento para a consolidação de sua dimensão educativo-consultiva.

Palavras-chave: ética em pesquisa, comissão de ética, revisão ética, bioética, educação

\section{Desarrollo de la dimensión educacional de los Comités de Ética en Investigación (CEPs)}

Resumen: La importancia del carácter educativo y consultivo de los comités de ética en investigación (CEIs) destaca el valor de estudios que indaguen esas dimensiones en dichos comités. Objetivos: analizar como los CEIs han realizado su papel educacional y consultivo; averiguar si los consultores tienen alguna formación sobre ética en investigación; identificar si los investigadores tuvieron orientaciones sobre ética en investigación en su trayectoria académica. Estudio cuantitativo y descriptivo, aprobado por el CEP/UESB bajo protocolo 134/2009, realizado con 95 informantes y analizado por el Software Sphinx. De acuerdo con los dados obtenidos, cerca de 71,5\% de los participantes de la investigación consideran las actividades educativas y consultivas realizadas por el CEI poco frecuentes o inexistentes; $60 \%$ de los consultores del CEI tienen algún tipo de formación ética y $66,7 \%$ de los investigadores participantes tuvieron alguna aproximación ética en su trayectoria académica. Estos datos indican que los CEIs necesitan mayor apoyo institucional e inversión para la consolidación de su dimensión educativo-consultiva.

Palabras clave: ética en investigación, comités de ética, revisión ética, bioética, educación

\section{Development of the educational dimension of ethics of research committees (ERCs)}

Abstract: The importance of the educational and consulting nature of ethics of research committees (ERCs) highlights the value of research which studies these dimensions in the committees. Aims: to analyze how ERCs have carried out their educational and consulting role; to learn whether advisors have some training in research ethics; to identify whether researchers had guidance about research ethics in their academic career. This is a quantitative and descriptive study approved by CEP/UESB under protocol 134/2009, carried out with 95 informants and analyzed by Software Sphinx. According to data obtained, nearly $71.5 \%$ research participants consider educational and consulting activities carried out by ERC infrequent or lacking; $60 \%$ participants have some ethical training in their academic career. These data show that ERCs need greater institutional support and funding in order to consolidate their educational-consulting dimension.

Key words: research ethics, ethics committees, ethical review, bioethics, education

\footnotetext{
${ }^{1}$ Graduada em Ciências Biológicas pela Universidade Estadual do Sudoeste da Bahia. Secretária do Comitê de Ética em Pesquisa da Universidade Estadual do Sudoeste da Bahia, Brasil

Correspondência: drybarbosa@yahoo.com.br

${ }^{2}$ Graduada em Enfermagem e Obstetrícia pela Universidade Federal da Bahia. Professora titular do Departamento de Saúde da Universidade Estadual do Sudoeste da Bahia, UESB, Brasil

${ }^{3}$ Graduado em Enfermagem pela Universidade Federal da Bahia. Professor Titular do Departamento de Saúde da Universidade Estadual do Sudoeste da Bahia, UESB, Brasil

${ }^{4}$ Análise de Sistemas pela Universidade Metodista de Piracicaba, Brasil
} 


\section{Introdução}

A dimensão educacional e consultiva dos Comitês de Ética em Pesquisa (CEPs), objeto deste estudo, discute a responsabilidade dos CEPs em educar pesquisadores plenos ou em formação para o exercício da pesquisa e da consultoria nessa área.

O primeiro Comitê de Ética surgiu nos Estados Unidos da América (EUA), em 1971, num contexto social em que as discussóes éticas foram se tornando mais freqüentes e complexas. Disto depreende-se que este órgáo possui uma grande amplitude de ação, encontrando-se relacionado à pesquisa, ao ensino, à prestação de consultorias e à proposição de normas institucionais referentes aos aspectos éticos, dentre outras funçóes(1).

No Brasil, os Comitês de Ética em Pesquisa (CEPs) são mais recentes e surgiram a partir da Resolução No 1/1988(2), do Conselho Nacional de Saúde (CNS). Os primeiros CEPs brasileiros estavam vinculados a hospitais, clínicas e serviços especializados, não sendo encontrados em locais onde a ética era objeto de ensino. Além disso, apesar de possuir uma composição multidisciplinar, estes CEPs não tinham sua composição e forma jurídica definidas, o que dificultava sua incorporação à prática de pesquisa(3).

Com o advento da Resolução No 196/1996(4) do Conselho Nacional de Saúde, os CEPs foram mais claramente definidos e se tornaram muito mais numerosos, adquirindo mais visibilidade e importância, inclusive no que concerne às instituições brasileiras de ensino e pesquisa.

Neste país os CEPs se caracterizam como um órgão de controle social em pesquisa definido pela Resolução No 196/1996(4) como colegiados interdisciplinares e independentes, com "múnus público", dotados de caráter consultivo, deliberativo e educativo, criados com o objetivo de defender os interesses dos participantes da pesquisa em sua integridade e dignidade com o intuito de contribuir para o desenvolvimento de pesquisas dentro dos padróes éticos.

Enfatizando o caráter educativo do CEP, o Ma- nual Operacional para Comitês de Ética em Pesquisa(5) lembra que o CEP deve assegurar a formação continuada dos seus membros, dos pesquisadores e dos participantes das pesquisas da instituição e promover a discussão dos aspectos éticos das pesquisas envolvendo seres humanos na comunidade, o que abrange não apenas a apreciação dos protocolos de pesquisa, mas também a criação de site do próprio CEP e a realização de eventos tais como seminários, palestras, cursos, dentre outros.

Além disso, dentre suas atividades educativas, o CEP também deve prestar consultoria, tanto para os pesquisadores na elaboraçáo e desenvolvimento do protocolo de pesquisa, como também para as instituições que desejem formar seu próprio CEP e promover a integraçáo e a troca de experiências com outros, no intuito de adquirir novos conhecimentos e fortalecer o CEP. Além disso, devem se empenhar em promover condições para estimular o desenvolvimento de estudos sobre temas relacionados à ética em pesquisa(5).

A bioética, ou ética aplicada à vida, é uma ciência essencialmente multi, inter e transdiciplinar, pois integra saberes de diversas áreas do conhecimento e ocupa-se de questôes relevantes à pessoa e à humanidade. $\mathrm{O}$ ensino da bioética, pois, deve ser integral e fazer parte da formação de todos os cidadãos $(6,7)$.

Assim, apesar de a bioética possuir interface com várias ciências, Azevêdo(8) lembra que a transdiciplinaridade no ensino é considerada difícil de ser alcançada devido à forma compartimentalizada de produçáo e transmissão do conhecimento através de disciplinas, o que descaracteriza a unidade presente nas ciências. Além disso, as sociedades modernas e pluralistas requerem profissionais que sejam capazes de reconhecer e lidar com conflitos éticos. Estes aspectos conduzem à indagação de quando, em que nível de ensino, e como deve dar-se o ensino de bioética, se como conteúdo inserido nas disciplinas já existentes ou como uma disciplina específica.

No Brasil, o ensino de bioética tem se dado nos níveis de graduação, aperfeiçoamento, especiali- 
zação e cursos de pós-graduação stricto sensu, além de existir, mais recentemente, formação acadêmica específica em bioética através de Programas de Pós-Graduação stricto sensu, em nível de mestrado e doutorado(8).

Messias et al.(9) ressaltam a importância de se ministrar a bioética já no ensino médio, uma vez que, devido às transformaçôes que vem ocorrendo em todos os campos da ciência e que repercutem nas práticas educacionais, torna-se imprescindível preparar os educandos para lidar com as implicaçōes éticas do conhecimento científico. Neste contexto do ensino médio, as discussões éticas podem emergir espontaneamente em diferentes disciplinas, tais como biologia, física, química, filosofia, história e geografia(10), sem necessariamente se aglutinarem em uma disciplina.

Para Gomes(11) o ensino da bioética é necessário aos médicos e demais profissionais de saúde, uma vez que, além de contribuir para a formação do caráter, é indispensável ao controle da vida e à manipulação do semelhante. Tal formação deve iniciar-se nas disciplinas básicas do estágio préclínico com noções de ética, introdução à bioética, ética aplicada ao ambiente, respeito ao cadáver, aos mestres, aos animais de experiência e à postura acadêmica.

Assim, neste contexto, tornam-se relevantes pesquisas como esta, que busquem investigar o papel educacional dos CEPs, a capacitação de seus membros e a existência ou não de abordagem ética na trajetória acadêmica dos pesquisadores. Nessa contextualização emergiram as seguintes questôes norteadoras: como os CEPs têm realizado seu papel educacional? Os membros do CEP participaram de algum evento ou curso sobre ética? Os pesquisadores tiveram alguma abordagem ética em sua trajetória acadêmica?

Para responder a estes questionamentos, foram elaborados os seguintes objetivos: analisar como os CEPs têm realizado seu papel educacional e consultivo; averiguar se os pareceristas têm alguma formação sobre ética em pesquisa; e identificar se os pesquisadores tiveram orientaçóes sobre ética em pesquisa em sua trajetória acadêmica.

\section{Metodologia}

Estudo integrante da dissertaçáo de mestrado "Entraves e Potencialidades dos Comitês de Ética em Pesquisa (CEPs) das Universidades Estaduais da Bahia” do Programa de Pós-Graduação em Enfermagem e Saúde da Universidade Estadual do Sudoeste da Bahia (PPGES/UESB), sustentada em 2010, caracterizada como uma pesquisa quantitativa e descritiva, aprovada pelo Comitê de Ética em Pesquisa da UESB sob protocolo No 134/2009 e realizada com quatro Comitês de Ética em Pesquisa do Estado da Bahia.

O cenário do estudo foi projetado para os quatro CEPs das quatro Universidades Estaduais da Bahia, mas como uma delas deixou de participar, o cenário foi constituído de três CEPs. Os dados foram coletados através de quatro tipos distintos de questionários, elaborados com essa finalidade e, considerando, o alcance dos objetivos. Eles foram respondidos eletronicamente, por e-mail, no período de dezembro de 2009 a maio de 2010. A amostra do estudo é composta de 95 (noventa e cinco) indivíduos, sendo eles pessoas que integram os CEPs e pesquisadores que já submeteram projetos de pesquisa aos CEPs participantes do estudo, selecionados de acordo com os critérios descritos a seguir.

Os pareceristas de CEP participantes da pesquisa foram selecionados através de sorteio por área de conhecimento a partir da relação de pareceristas do CEP. Se uma área de conhecimento era representada por mais de uma pessoa, foi realizado o sorteio entre as pessoas da mesma área do conhecimento para selecionar o participante. Em caso de não aceitação da pessoa sorteada, era realizado novo sorteio. Todos os presidentes/coordenadores e secretários dos CEPs estudados foram convidados a participar do estudo, embora apenas metade deles (2 de cada grupo) aceitou participar. Um dos CEPs não forneceu a relaçáo de pareceristas, impossibilitando que os mesmos fossem convidados a participar do estudo.

Os pesquisadores foram, em sua maioria, selecionados através dos Diretórios dos Grupos de Pesquisa da Plataforma Lattes com o emprego dos 
critérios para identificação de realização de pesquisas envolvendo seres humanos estabelecidos por Barbosa(12). Alguns pesquisadores também foram contatados com o auxílio de alguns dos CEPs participantes.

Todos os convidados a participar da pesquisa receberam um e-mail convite apresentando a pesquisadora e fornecendo esclarecimentos sobre a pesquisa e sua importância. Anexos ao e-mail convite encontravam-se o questionário específico à categoria participante e o Termo de Consentimento Livre e Esclarecido (TCLE).

Os dados obtidos com os questionários constituíram um banco de dados no Software Sphinx Léxica for Windows, versão 5.0 em português, os quais foram analisados quantitativamente com o emprego da Estatística Descritiva e dispostos em quadros.

\section{Resultados}

Ao serem perguntados se o CEP já havia realizado algum evento e/ou curso, cerca de $75 \%$ dos participantes da pesquisa que faziam parte da secretaria e da presidência/coordenação do CEP, afirmaram que sim, enquanto $25 \%$ afirmou que não. Todavia, quando perguntamos a todos os participantes da pesquisa sobre a realização, pelo CEP, de atividades de sensibilizaçáo dos pesquisadores sobre a importância da ética em pesquisa, $71,5 \%$ dos participantes informaram que tais atividades encontram-se entre pouco freqüentes e inexistentes, enquanto $18,9 \%$ afirmaram ser freqüente ou suficiente. As respostas, "muito freqüente" $(1,1 \%)$ e "outro" $(8,4 \%)$ também foram citadas (quadro 1). Dentre estas últimas, destacamos:

Também desconheço - Mesmo o trabalho de esclarecimento sobre a necessidade e o funcionamento do CEP.

Acontece de acordo com o pedido de coordenadores de cursos.

Todo o semestre tem atividade para os pesquisadores. Não vejo divulgação rotineira.

No início houve muitas discussóes, seminários. Filosoficamente entendemos a sua concepção, mas não compreendemos a sua efetivação. Em primeiro lugar deveria valorizar a politica de construção da pesquisa na universidade, traçar metas coerentes e significativas com a pesquisa de relevância social. Assim, as questóes éticas já estariam presentes.

\begin{tabular}{|l|l|l|}
\hline $\begin{array}{l}\text { Atividades de } \\
\text { sensibilizaçáo dos } \\
\text { pesquisadores sobre } \\
\text { a importância da } \\
\text { ética em pesquisa }\end{array}$ & $n$. & $\%$ \\
\hline Inexistente & 33 & $34,7 \%$ \\
\hline pouco freqüente & 35 & $36,8 \%$ \\
\hline Suficiente & 8 & $8,4 \%$ \\
\hline Freqüente & 10 & $10,5 \%$ \\
\hline muito freqüente & 1 & $1,1 \%$ \\
\hline Outro & 8 & $8,4 \%$ \\
\hline Total & 95 & $100,0 \%$ \\
\hline
\end{tabular}

Quadro 1: Realizaçáo de atividades de sensibilização sobre a importância da ética em pesquisa, do estudo Entraves e potencialidades dos Comitês de Ética em Pesquisa (CEPs) das Universidades Estaduais da Bahia. Jequié/BA, 2010.

Ao serem perguntados se o CEP prestava suporte para a formação de outro CEP, $41,4 \%$ dos componentes de CEP participantes deste estudo informaram que às vezes, $17,2 \%$ relataram que nunca e 10,3\% disseram que frequentemente. A opção sempre não foi citada e a opção outro foi citada por $27,6 \%$ dos componentes de CEP que participaram deste estudo (quadro 2). Devemos lembrar que alguns participantes assinalaram uma resposta, mas manifestaram-se também na opção outro. Dentre as respostas agrupadas como "outro", destacamos:

O CEP parece que ainda náo foi consultado para este fim, embora tenhamos a vontade de que outras 
instituiçôes na região se interessem por formar seus CEP e que possamos trabalhar de forma integrada. O que percebo é que não existe disponibilidade das instituiçóes em formar seus CEP's.

\begin{tabular}{|l|l|l|}
\hline $\begin{array}{l}\text { Prestaçáo de suporte } \\
\text { para formaçáo de } \\
\text { outros CEPs }\end{array}$ & $n$. & $\%$ \\
\hline Nunca & 5 & $17,2 \%$ \\
\hline às vezes & 12 & $41,4 \%$ \\
\hline várias vezes & 1 & $3,4 \%$ \\
\hline Frequentemente & 3 & $10,3 \%$ \\
\hline Sempre & 0 & $0,0 \%$ \\
\hline Outro & 8 & $27,6 \%$ \\
\hline Total & 29 & $100,0 \%$ \\
\hline
\end{tabular}

Quadro 2: Prestação de suporte para formação de outros CEPs, do estudo Entraves e potencialidades dos Comitês de Ética em Pesquisa (CEPs) das Universidades Estaduais da Bahia. Jequié/BA, 2010.

No que concerne ao ensino da bioética por instituições de educação, cerca de $66,7 \%$ dos pesquisadores participantes da pesquisa tiveram alguma abordagem sobre ética em pesquisa na trajetória acadêmica, enquanto 33,3\% afirmaram não ter tido nenhuma. Dentre os pesquisadores que tiveram alguma abordagem ética na trajetória acadêmica, a maior parte deles teve estas abordagens na graduação $(25,9 \%)$ e/ou mestrado $(24,1 \%)$ nas disciplinas Metodologia $(33,3 \%)$ e/ou Bioética $(23,8 \%)$ e/ou Ética em Pesquisa (9,5\%), uma vez que era possível ao pesquisador participante especificar quantas disciplinas e momentos acadêmicos fossem necessários. Cerca de 11,1\% deles também informou ter participado de algum evento e/ou curso sobre ética.
Dados semelhantes, encontramos quando perguntamos se os pareceristas dos CEPs participantes deste estudo já haviam participado de algum evento ou curso sobre ética em pesquisa, uma vez que $40 \%$ deles afirmaram que não, enquanto $60 \%$ afirmaram que sim.

\section{Discussão}

No que concerne à realização de atividades educativas, a diferença entre o relatado pelo CEP e o que foi informado por cerca de $71,5 \%$ dos participantes pode ser atribuída a vários fatores, tais como: a diferença na quantidade de pessoas que responderam estas questões, uma vez que o universo de componentes da secretaria e da presidência/coordenação do CEP é menor do que o universo total de participantes deste estudo, as diferenças de realidade entre os CEPs, a pequena divulgação de eventos/cursos realizados pelo CEP, a possíveis dificuldades do CEP em realizar eventos/cursos e até ao desconhecimento dos participantes da pesquisa sobre a freqüência de realização ou não pelo CEP de atividades de sensibilização dos pesquisadores.

A Resolução No 196/1996(4), já em seu capítulo II "Termos e Definições", ao definir o que são os Comitês de Ética em Pesquisa, deixa claro o seu papel educativo ao especificar que se trata de um órgão provido de caráter consultivo, deliberativo e educativo. Mais adiante, reforça este aspecto ao especificar que uma das atribuições do CEP é "desempenhar papel consultivo e educativo, fomentando a reflexão em torno da ética na ciência"(4:7).

O Manual Operacional para Comitês de Ética em Pesquisa(5) reforça ainda mais este aspecto ao afirmar que o CEP deve exercer papel educativo para assegurar a formação continuada dos pesquisadores da instituição, promovendo discussóes e reflexôes éticas. Ainda segundo o manual, as açôes educativas do CEP devem abranger também os participantes das pesquisas, a comunidade institucional e a comunidade em geral, podendo ser realizadas também consultorias para os pesquisadores sobre a elaboração do projeto e durante o desenvolvimento do mesmo. Dentre as formas 
de realização de atividades educativas, o manual orienta que:

O papel educativo também pode ser desempenhado mediante a realizaçáo de reunióes, seminários, mesas-redondas, grupos de discussão, criação de página eletrônica (site) e outros meios que possibilitem reflexão e discussão de temas éticos, casos com dilemas especificos e situaçôes conflituosas(5:51).

Pizarro(13) defende que o ensino de bioética seja ministrado na graduação para educandos de todas as formaçóes, uma vez que conhecimentos de bioética podem contribuir para aprimorar a formaçáo profissional do educando, independente da área do conhecimento, através do debate de temas sob a óptica de várias disciplinas, o que propicia a possibilidade de utilização de diversos saberes.

Disto se depreende que a bioética tem se tornado cada vez mais relevante em todas as áreas do conhecimento, seja no exercício profissional ou na realização de pesquisa que envolva seres vivos, notadamente seres humanos. Isso torna ainda mais importante o papel educacional dos CEPs e o ensino da bioética, o qual deve ser realizado em todos os níveis educacionais (do fundamental à pós-graduação). No contexto atual, ambos - os CEPs e as instituiçóes de ensino - tem um papel fundamental no que concerne à formação de cidadãos éticos e capazes de reconhecer e lidar com conflitos éticos. Para tanto, se faz necessário, a formação de pesquisadores eticamente responsáveis, que desenvolvam pesquisas comprometidas com o respeito à vida em todas as suas formas e, notadamente, com a integridade da pessoa humana.

Os CEPs podem enfrentar dificuldades para realizar seu papel educativo intra e extramuros das instituições que os abrigam. Tais dificuldades relacionam-se com a precária infra-estrutura de alguns dos CEPs participantes, seu pequeno número de funcionários, grande demanda de projetos submetidos para revisão ética, a sobrecarga de trabalho de todos os componentes do CEP, o pequeno apoio institucional, a falta de interesse (muitas vezes motivado pelo desconhecimento) da comunidade acadêmica em participar de algum evento ligado ao CEP, a falta de financiamento/ orçamento institucional destinado a eventos de alguns dos CEPs participantes deste estudo. Isso, muitas vezes, impóe ao CEP concorrer a editais de custeio de eventos de órgãos de fomento à pesquisa, o que demanda um grande tempo (do qual nem sempre os CEPs dispóem) para a elaboração do projeto para submissão e expóe o $\mathrm{CEP}$ ao risco de se submeter a potenciais conflitos de interesse, uma vez que os órgãos de fomento à pesquisa possuem interesse direto na aprovação pelo CEP das pesquisas que financiam.

Além dessas dificuldades, a constante renovação dos discentes e a exigência de realização de trabalhos de pesquisa para a conclusão dos cursos de graduação atribuem ao CEP uma demanda incessante de atividades educativas continuadas, as quais dificilmente o CEP tem condições de corresponder, uma vez que sua capacidade de trabalho não tem crescido de acordo com o aumento de suas demandas(14).

Neste contexto, a CONEP tem estimulado a realização de eventos de divulgação dos CEPs e a discussáo sobre ética em pesquisa com os pesquisadores das instituiçóes que realizam pesquisas, o que pode contribuir para a conscientização dos mesmos sobre a importância da submissão dos projetos de pesquisa aos CEPs no intuito de garantir a integridade das pesquisas e preservar os seus participantes(15).

A realização de atividades educacionais pelo CEP favorece o desenvolvimento de sua credibilidade na instituiçáo que o abriga(1), todavia devemos lembrar que o apoio institucional oferecido ao CEP é de fundamental importância para que o mesmo realize as suas atividades funcionais, inclusive as educacionais e de consultorias.

O oferecimento de suporte para formação de outro CEP é uma consultoria que deve ser fornecida, fazendo também parte das atividades de caráter educativo e consultivo que o CEP desempenha; além disso, contribui para o processo de integração, troca de experiências e compartilhamento de saberes entre um CEP mais antigo, portanto mais experiente, e um CEP mais jovem 
ou ainda em formação, sendo preconizado pelo Manual Operacional para Comitês de Ética em Pesquisa(5) como uma das formas de relacionamento entre CEPs.

De acordo com Tavares-Neto et al.(16) o CEP/ UEFS, um dos CEPs participantes deste estudo, tem contribuído para a formação de outros CEPs, inclusive os CEP/UESB, CEP/UESC e CEP/ UNEB (os outros CEPs participantes deste estudo), através de palestras sobre a criação e desenvolvimento das atividades de um CEP.

É importante ressaltar também que o CEP/UESB já realizou palestras nos campi da UESB de Vitória da Conquista e Itapetinga, considerando tratar-se de uma universidade multicampi, conclamando estes Campi a implantarem seus próprios CEP e que nos anos de 2009 e 2010 ofereceu-se para prestar suporte para que outras instituiçóes da Região Sudoeste da Bahia implantem seus CEPs, inclusive enviando ofícios no intuito de sensibilizá-las à implantação. Quando o oferecimento de suporte foi realizado por telefone, essas instituições agradeceram a boa vontade do CEP, mas até o presente momento náo fizeram novos contatos para que o suporte pudesse ser concretizado. Os outros campi da UESB parecem ainda não ter tomado iniciativas para implantar seus CEPs apesar dos contínuos alertas do CEP/UESB sobre a necessidade de constituição dos mesmos.

Neste sentido, lembramos que a implantação de um CEP traz custos, mas não um retorno financeiro direto para a instituição que o abriga, fazendo com que a importância da sua constituição e atuação não seja percebida pelas instituiçóes e pesquisadores, uma vez que o retorno obtido pelas instituiçôes é a consolidação ético-científica de sua vocação para a pesquisa, o que pode vir a refletir em uma produçáo científica de maior qualidade e, consequentemente, em um maior número de projetos financiados por órgãos de fomento e em uma elevação na quantidade de artigos científicos publicados, conforme lembra o Manual Operacional para Comitês de Ética em Pesquisa ao afirmar que "a existência de um CEP na instituição, qualifica-a e legitima sua vocação para a pesquisa”" (5:13).
A maior parte dos pesquisadores participantes teve alguma abordagem ética na trajetória acadêmica, todavia é importante ressaltar que um número expressivo deles $(33,3 \%)$ não teve nenhuma abordagem ética na trajetória acadêmica. O estudo da bioética e da ética em pesquisa na trajetória acadêmica em todos os níveis e em todas as formaçôes profissionais é fundamental, pois auxilia o desenvolvimento de pesquisas dentro dos mais altos padróes éticos, respeitando os direitos e a integridade física, moral e psicológica de todos os participantes.

Além disso, abordagens éticas na trajetória acadêmica podem auxiliar também na vida social e no convívio com outras pessoas e no próprio exercício profissional. Vale considerar que, durante sua atuação profissional, todo e qualquer profissional, independente da área do conhecimento, pode se deparar com situaçóes que envolvam dilemas éticos e que demandem conhecimento de ética e reflexão para serem resolvidos. Soma-se a isso também o fato de que é cada vez maior o número de pessoas que tem ingressado nos cursos de graduação e pós-graduação e que o Ministério da Educação e Cultura (MEC) do Brasil exige que todo curso acadêmico seja finalizado com um trabalho científico.

A capacitação dos membros do CEP deve ser contínua, ocorrendo não apenas durante as reuniōes, mas também em eventos e cursos promovidos pelo CEP e durante a própria formação acadêmica, uma vez que, ao revisar eticamente um protocolo, o parecerista precisa ter conhecimento de ética em pesquisa para avaliá-lo científica e eticamente e perceber a existência de conflitos de interesses, a dimensão dos desconfortos e/ou riscos, os possíveis benefícios ao indivíduo e/ou coletividade e se estes se sobrepóem àqueles de forma a justificar a pesquisa e conferir-lhe relevância social, preservando os direitos, a dignidade e a integridade biopsicossocial dos participantes do estudo.

Neste contexto, as atividades e as reunióes do CEP não devem ser apenas direcionadas à revisão ética dos projetos de pesquisa, mas também es- 
paços para a reflexão ética e a formação dos pareceristas. De acordo com Novaes e Guilhen(17), o desenvolvimento de programas de educação permanente dos membros do CEP é essencial para que o CEP cumpra seu papel de forma efetiva e fortaleça suas práticas de revisão ética dos protocolos de pesquisa.

\section{Consideraçóes finais}

Os dados encontrados demonstraram que, embora $66,7 \%$ dos pesquisadores e $60 \%$ dos pareceristas de CEP participantes desta pesquisa tenham tido alguma abordagem ética na trajetória acadêmica e algum tipo de capacitaçáo formal sobre ética em pesquisa, respectivamente, é expressivo o quantitativo de pesquisadores e pareceristas de CEP que nunca tiveram nenhuma instrução ou capacitação formal nesta área. A abordagem ética na trajetória acadêmica é fundamental para o posicionamento ético-crítico de qualquer profissional, independente de sua área do conhecimento, no desempenho de suas funçóes, uma vez que dilemas éticos podem aparecer em qualquer profissão. É importante também a existência de capacitação para que os pareceristas sejam capazes de perceber mais claramente os aspectos éticos envolvidos nas pesquisas que apreciam e, principalmente, a existência ou não de conflitos de interesse, bem como os riscos e benefícios aos quais os participantes da pesquisa estarão expostos, emitindo assim pareceres com maior qualidade e fundamentados nos prefeitos éticos da Resolução No 196/1996 e suas complementares.

Devemos ressaltar, ainda, que conhecimento de ética é fundamental para a realização de toda e qualquer atividade de pesquisa, envolvendo ou não seres humanos, e para a apreciação de projetos de pesquisa no CEP e que os dados encontrados por este estudo refletem as poucas atividades educativas realizadas pelos CEPs (consideradas pouco freqüentes ou inexistentes por $71,5 \%$ dos participantes da pesquisa) e a necessidade da existência de programas de educação continuada para os membros do CEP. Atividades estas que demandam maior apoio institucional e investimento no desenvolvimento e consolidação dos CEPs.

Além disso, os achados deste estudo indicam que muitas instituições parecem possuir dificuldades ou náo ter interesse em criar seu próprio CEP, uma vez que sua criaçáo demanda custos e seu retorno à instituição que abriga o CEP, embora fundamental, não seja direto, transparecendo no incremento à pesquisa, no aumento da qualidade da mesma, no crescimento da proteção e respeito aos participantes da pesquisa e no desenvolvimento da consciência ética em todos os níveis de ensino da instituição. 


\section{Referências}

1. Feijó AG dos S. A função dos comitês de ética institucionais ao uso de animais na investigação científica e docência. Revista Bioética 2004; 12(2): 11-22.

2. Brasil. Resolução No 01 de 13 de junho de 1988. Conselho Nacional de Saúde. [capturado 20 set. 2008]. Disponível em: http://www.ufrgs.br/bioetica/r01-88.htm

3. Novaes MRCG, Guilhem D, Lolas F. Dez anos de experiência do Comitê de Ética em Pesquisa da Secretaria de Saúde do Distrito Federal, BRASIL. Acta Bioethica 2008; 14(2): 185-192.

4. Brasil. Resolução No 196 de 10 de outubro de 1996. Conselho Nacional de Saúde.

5. Brasil. Ministério da Saúde. Conselho Nacional de Saúde. Manual Operacional para Comitês de Ética em Pesquisa. Brasília: Ministério da Saúde; 2006.

6. Garrafa V. Multi-inter-transdisciplinaridad, Complejidad y Totalidad Concreta. In: Garrafa V, Kottow M, Saada A, (org.) Estatuto Epistemológico de la Bioética. México: UNAM, Instituto de Investigaciones Jurídicas; 2005: 67-85.

7. Clotet J. Bioética como Ética Aplicada e Genética. Revista Bioética 1997; 5(2): 173-183.

8. Azevêdo EE de S. Ensino de Bioética: um desafio transdisciplinar. Interface - Comunic, Saúde, Educ 1998; 2(2): 127-138.

9. Messias TH, Anjos MF, Rosito MMB. Bioética e educação no ensino médio. Bioethikos 2007; 1(2): 96-102.

10. Lenoir N. O Ensino de Bioética no Mundo. Bioética 1996; 4: 65-70.

11. Gomes JCM. O Atual Ensino da Ética para os Profissionais de Saúde e seus Reflexos no Cotidiano do Povo Brasileiro. Bioética 1996; 4: 53-64.

12. Barbosa AS. Entraves e Potencialidades dos Comitês de Etica em Pesquisa (CEPs) das Universidades Estaduais da Bahia. Jequié; 2010. Mestrado [Dissertação] - Programa de Pós-Graduação em Enfermagem e Saúde, Universidade Estadual do Sudoeste da Bahia.

13. Pizarro MAP. Bioética na Graduação. Anais do Fórum Internacional Integrado de Cidadania, Educação, Cultura, Saúde e Meio Ambiente. 26-29 abr. 2006, Santo Ângelo, Brasil. Santo Ângelo: Universidade Regional Integrada do Alto Uruguai e das Missóes; 2006.

14. Santos ML, et al. Protocolo de pesquisa: o desafio do aprimoramento ético. Revista Bioética 2010; 18(1): 201-211.

15. Jorge MT, Pegoraro BL, Ribeiro LA. Abrangência de ação do Comitê de Ética em Pesquisa da Universidade Federal de Uberlândia. Revista Bioética 2007; 15(2): 308-316.

16. Tavares-Neto J, Azevêdo ES, Gomes M da GS. Breve história da Bioética na Faculdade de Medicina da Bahia, UFBA, E NA Universidade Estadual de Feira de Santana, Bahia. Gaz Méd. Bahia 2007; 77(1): 19-30.

17. Novaes MRCG, Guilhen D. Comitês de Ética em Pesquisa e os Desafios da Educação Permanente. Brasilia Med 2009; 1(Supl 1): 42-50.

Recebido: 16 de fevereiro de 2011

Aceito: 18 de março de 2011 